\title{
Significance of Skull IX in Asian Paleoanthropology
}

\author{
Yousuke Kaifu
}

The University Museum, The University of Tokyo, Japan

\begin{abstract}
Skull IX (Tjg-1993.05) was found in Sangiran, Central Java, in 1993, and is now stored at the Institute of Technology, Bandung. It is a remarkably complete fossil cranium of Homo erectus. It is one of the six $H$. erectus crania from the early Pleistocene of Java that preserves a nearly complete vault and is the third Javanese $H$. erectus crania with a substantial part of the facial skeleton preserved. After preliminary studies by late Prof. Sartono and other researchers, our team, led by Prof. Yahdi Zaim, had an opportunity to re-reconstruct and fully describe the specimen during 2008-2010. In this paper, I introduce how we corrected the distorted original reconstruction and summarize the specimen's implications for the Homo erectus evolution in and outside Indonesia. Skull IX closely resembles Sangiran 17 and other Javanese $H$. erectus crania from the same stratigraphic level. The neurocranium of Skull IX is slightly smaller than the so-far-recorded smallest cranium from this zone, suggesting this individual was female. The face exhibits some "Asian" features, which highlights regional variation in Afro-Asian archaic members of Homo.
\end{abstract}

Keywords: Homo erectus, Skull IX, Sangiran, Java

\footnotetext{
Copyright (C2021. FOSI. All rights reserved.

A Special Publication of abstracts and extended abstracts from the conference in honor of the retirement of Prof. Yahdi Zaim, IPU (22-23 March 2021).
}

DOI: $10.51835 /$ bsed.2021.47.3.354 